\title{
Attriters and Bilinguals: What's in a Name?
}

\author{
Federico Gallo ${ }^{1,2 *}$, Keerthi Ramanujan ${ }^{1}$, Yury Shtyrov ${ }^{1,3}$ and Andriy Myachykov ${ }^{1,4}$ \\ ${ }^{1}$ Centre for Cognition and Decision Making, Institute for Cognitive Neuroscience, HSE University, Moscow, Russia, ${ }^{2}$ Centre \\ for Neurolinguistics and Psycholinguistics, Vita-Salute San Raffaele University, Milan, Italy, ${ }^{3}$ Center of Functionally Integrative \\ Neuroscience, Aarhus University, Aarhus, Denmark, ${ }^{4}$ Department of Psychology, Northumbria University, Newcastle upon \\ Tyne, United Kingdom
}

The use of language as a universal tool for communication and interaction is the backbone of human society. General sociocultural milieu and specific contextual factors can strongly influence various aspects of linguistic experience, including language acquisition and use and the respective internal neurolinguistic processes. This is particularly relevant in the case of bilingualism, which encompasses a diverse set of linguistic experiences, greatly influenced by societal, cultural, educational, and personal factors. In this perspective piece, we focus on a specific type of linguistic experience: non-pathological first-language $(L 1)$ attrition - a phenomenon that is strongly tied to immersion in non-L1 environments. We present our view on what may be the essence of $L 1$ attrition and suggest ways of examining it as a type of bilingual experience, in particular with relation to its neurocognitive bases.

OPEN ACCESS

Edited by:

Ramesh Kumar Mishra

University of Hyderabad, India

Reviewed by:

Arturo Hernandez,

University of Houston, United States Meesha Alecia Warmington,

The University of Sheffield, United Kingdom

*Correspondence: Federico Gallo fgallo@hse.ru

Specialty section: This article was submitted to

Language Sciences, a section of the journal Frontiers in Psychology

Received: 01 May 2020 Accepted: 14 June 2021

Published: 15 July 2021

Citation:

Gallo F, Ramanujan K, Shtyrov Y and Myachykov A (2021) Attriters and

Bilinguals: What's in a Name?

Front. Psychol. 12:558228.

doi: 10.3389/fpsyg.2021.558228
Keywords: bilingualism, L1 attrition, bilingual experience, L2 immersion, sociocultural changes

\section{INTRODUCTION}

Globalization and mobility are increasingly establishing themselves as defining features of current world. Reports of the United Nations highlight a steady yearly growth in migration; in the last 20 years, the phenomenon doubled in magnitude, with the number of migrants reaching the figure of 260 million in 2017 (United Nations, 2018). As a result of such mobility, alongside changes in educational requirements, and internationalization of the job market, more than half of the world population is currently estimated to be bilingual (e.g., Grosjean, 2010). For instance, bilingual citizens constitute $21.5 \%$ of the grand total in the United States population (American Community Survey, 2015), 17.5\% in Canada (Canada Census Program, 2011), and 54\% in the European Union, where over $90 \%$ of the bilingual population reached peaks in some countries (Eurobarometer Report "Europeans and their languages", 2012). A unique challenge for the bilingual mind is the simultaneous storage and management of two or more linguistic codes, which have been shown to be in a constant interaction with each other. In fact, a considerable amount of literature has investigated and demonstrated the influence of the first-language (L1) on the second one (L2; e.g., Dijkstra and Van Heuven, 2002). The equally important and plausible effects of the L2 on the native language have received much less attention. Here, we focused on one specific type of language experience that is closely associated with the latter-L1 attrition-the non-pathological, gradual decrease of native language performance that takes place alongside with, and even without (Baladzhaeva and Laufer, 2018), increase in L2 proficiency (Köpke and Schmid, 2004). Research on L1 attrition emerged in the early 1980s, and at present, almost 40 years later, still occupies a relative niche in the field of bilingualism. Nonetheless, a great progress has been made in the last two decades, due to a remarkable effort from attrition researchers to affine definitions and develop tools to investigate the phenomenon and its underlying mechanisms. 
In this short opinion piece, after briefly defining the concept of L1 attrition and reviewing its putative underlying mechanisms, we advocated for the continuation and reinforcement of a trend put forward by attrition researchers in the last 15 years, unifying the characters of the bilingual and the attriter within the shared theoretical framework of crosslinguistic interaction. Our goal is to appeal to "traditional bilingualism" researchers to firmly establish the attrition phenomenon in empirical investigations as well as in theoretical platforms, as accounting for "the other side of the coin" can help to shed light on the neural and cognitive phenomena of the bilingual mind.

\section{WHAT IS L1 ATTRITION?}

Among the many existing characterizations of this phenomenon, described by Köpke (2004) as a "terminological jungle," L1 attrition has been broadly defined as "any of the phenomena that arise in the native language of a sequential bilingual as the consequence of the co-activation of language, crosslinguistic transfer or disuse" (Schmid and Köpke, 2017a, p. 637) ${ }^{1}$. Guided by this view of L1 attrition, there has been an extensive characterization and a detailed analysis of how the linguistic behaviors of bilingual attriters, particularly those who are captured in productive language and "offline" tasks, contrast with those of monolingual speakers. Examples of such studies include research in L1 accent/phonology attrition (Bergmann et al., 2016; de Leeuw et al., 2018), analyses of morphosyntactic reconfigurations (Karayayla and Schmid, 2019), and the changes in L1 fluency and complexity induced by L2 exposure (Schmid and Jarvis, 2014; Bergmann et al., 2015a). From this viewpoint, linguistic behavioral deviations from monolingual standards are considered as indicative of $\mathrm{L} 1$ attrition. While there is extensive evidence of L1 attrition arising from L2 interference (see, Köpke and Schmid, 2004; Schmid and Köpke, 2017a), some studies also report L1 attrition occurring in the absence of an L2. For example, Laufer and Baladzhaeva (2015) and Baladzhaeva and Laufer (2018) investigated lexical, grammatical, and morphosyntactic L1 attrition in a sample of Russian immigrants in Israel with no knowledge of Hebrew as L2, comparing them with immigrant Russian/Hebrew bilinguals and Russian monolinguals still residing in Russia. Their results suggested that L1 linguistic behavior is susceptible to change even without the explicit knowledge of an intervening linguistic system. While L2 interference might still have made a contribution to L1 attrition in the latter case via a possible passive exposure to Hebrew spoken within the bilingual Russian immigrant population, the lack of explicit knowledge of L2 in the attriting population indicates a potentially intricate and complex nature of the attrition phenomenon.

This intricate phenomenological nature begs the following question: What is L1 attrition? To answer this question, we (1) raised two more questions of why and how it occurs, reviewing

\footnotetext{
${ }^{1}$ Here, guided by our abovementioned aim of generalizing L1 attrition to bilingualism research, we decided to adopt this rather broad definition as a starting point, but note that other definitions have been formulated. For an extensive review, see Köpke (2004).
}

recent findings and (2) endorsed a research strategy that builds upon and might contribute to recent developments aimed at unifying attrition and bilingual research fields. We acknowledged that, in posing these questions, there is an unavoidable circularity problem-each question rests on the assumption that L1 attrition is already defined despite this being the very thing that one hopes to achieve (we discussed a possible solution in section "Who is the L1 attriter-a bilingual by another name?"). Nevertheless, the answers to these interconnected questions may contribute toward qualifying the phenomenon of L1 attrition, and equally importantly they may help us understand how L1 attrition relates (and, essentially, belongs) to the general phenomenon of bilingualism.

\section{Question 1: Why Does Attrition Occur?}

First, there appears to be a certain selectivity of L1 attrition effects, i.e., there is considerable interindividual variation both in the severity of its "symptoms" and in the types of linguistic structures and systems it affects (Schmid, 2014). Thus, an alternative question, and perhaps one that is more specific would be, "When does attrition occur?"-i.e., under what specific conditions are L1 attrition effects most likely to appear?

It may be informative to begin by considering a situation in which L1 attrition disappears. A return (even if temporary) to the L1-dominant/native environment induces a rapid reversal of L1 attrition effects (e.g., Chamorro et al., 2016b; Gargiulo and van de Weijer, 2018; Köpke and Genevska-Hanke, 2018). On the one hand, this phenomenon suggests a potential role by the relative quantity and quality of contact with $\mathrm{L} 1$ as reimmersion in the L1-dominant environment brings better, more frequent opportunities to use L1 of an individual. On the other hand, it reinforces the role of L2 in inducing and driving changes in L1 as contact with L2 is naturally reduced upon a return to the L1 environment. In fact, experimental evidence has pointed at quantity (e.g., de Bot et al., 1991; Isurin, 2007; Opitz, 2013; Bergmann et al., 2016; Chamorro et al., 2016b; Kasparian et al., 2017; Schmid and Yilmaz, 2018; Karayayla and Schmid, 2019) and quality (e.g., Schmid, 2007; de Leeuw et al., 2010; Schmid and Dusseldorp, 2010; de Leeuw et al., 2012; Yilmaz and Schmid, 2012) of L1 exposure and at L2 interference (e.g., Ben Rafael, 2001; Dussias, 2004; Hutz, 2004; Ventureyra et al., 2004; Ribbert and Kuiken, 2010; Schmid and Jarvis, 2014; Chamorro et al., 2016a; de Leeuw et al., 2018) as factors contributing to the presence and the severity of L1 attrition.

Besides these main causal factors, however, research has also highlighted a number of other key variables that can shape the L1 attrition experience of an individual, including the length of residence in an L2-dominant country, age of migration, attitude toward L1 and L2, communal/social identity and affiliation, extent of social integration, socioeconomic status, and age. Since an extensive and detailed review of experimental findings goes beyond the scope of this opinion, we redirected the reader to a recent work by Schmid et al. (2019) and references therein for a thorough account of existing evidence. It is important, however, to note that these factors are not exclusive to L1 attrition, but that they also contribute to variation in the bilingual experience per se. Nevertheless, taking together both the selectivity and reversibility 
of L1 attrition effects, it seems that whatever L1 attrition is, it does not appear to involve the actual erasure of tacit linguistic knowledge or representations. This brings us to the next question.

\section{Question 2: How Does Attrition Occur?}

Considering what we know thus far, one might ask: Is L1 attrition a stand-alone phenomenon, resulting (perhaps temporarily) from a qualitative and quantitative reduction in L1 use (with or without L2 exposure) or does it emerge due to the words, categories, and rules of L2 interfering with those of L1? Exploring what L1 attrition looks like in the mind and the brain of those experiencing it may help us find possible answers to this question.

Changes in observable linguistic behavior (measured using free speech and "offline" grammaticality judgments) and productive language suggest a possible change in the underlying neuro-psycho-linguistic processes that support such behaviors. The detailed analyses and descriptions of L1 attrition tell us how it may manifest at the behavioral end point (see text footnote 1 for examples of such studies). However, behavioral investigations alone can only hint at neurocognitive mechanisms underlying L1 attrition. Electrophysiological and neuroimaging techniques permit simultaneous investigations of both ends of the brain-behavior loop. Thus, examining "L1 attrition" from the point of view of how L1 language processing mechanisms have (or have not) changed might potentially bridge the existing brain-behavior knowledge gap in these studies (see Kasparian and Steinhauer, 2017b; Smith, 2019, for a similar view). In fact, such studies have emerged in recent years (see Schmid et al., 2019, for a comprehensive collection), and they reveal very interesting findings. For instance, using electrophysiological measures (ERPs-event-related potentials), Kasparian et al. (2017) and Kasparian and Steinhauer (2016, 2017a) have shown that certain forms of L1 morphosyntactic processing in L1 attriters are indeed different from that of nonattriting monolinguals.

One advantage of studying L1 attrition using neurophysiological and neuroimaging techniques is that it can help uncover neurocognitive features possibly characterizing attrition even in instances where it does not manifest in external linguistic behaviors. For example, some studies show that attriting bilinguals perform no differently than the nonattriting controls in offline behavioral sentence judgments, while the ERP data show specific group differences: for instance, where German monolinguals exhibit a posterior P600 effect to verb form violations, attriters show a biphasic N400-P600 pattern (Bergmann et al., 2015a). Similarly, Italian attriters display a more temporally distributed late $\mathrm{P} 600$ in response to anomalous sentences, while non-attriting peers exhibit only small P600 effects (Kasparian and Steinhauer, 2016). Taken together, these findings suggest that despite offline linguistic performance parity, underlying neurocognitive computations in L1 attriters proceed somewhat differently. In fact, investigating L1 attrition by capturing internal neurolinguistic and neurocognitive processes will be particularly useful in understanding the various attrition experiences (e.g., Laufer and Baladzhaeva, 2015), going beyond their apparent external presentations.

\section{WHO IS THE L1 ATTRITER-A BILINGUAL BY ANOTHER NAME?}

The two questions posited above motivate a very important third question: Who are L1 attriters? Are they defined by (1) external circumstances, e.g. immigration to an L2 environment, (2) their apparent linguistic behaviors, e.g., changes/reconfigurations in L1 production or offline performance deviations involving L1 morphosyntax, or (3) a specific set of internal neurocognitive states and processes? Equally important question is that is attrition really that separable or distinct from bilingualism per se?

It is recalled that Schmid and Köpke (2017a) regarded L1 attrition to be the "effect of the second language on the first" and, by relabeling the crosslinguistic influence of L2 on L1 as L1 attrition, they highlighted that "all bilinguals are attriters" (Schmid and Köpke, 2017b). Here, we shifted the focus to the complementary argument that "all attriters are first and foremost bilinguals" to highlight the point that L2 $\rightarrow$ L1 effects are non-separable from bilingualism and that "attrition" is indeed a sub-phenomenon of bilingualism. In fact, the key point of $\mathrm{L} 1$ attrition research is that not only the L1 influences the L2 but the L2 also affects the L1. A different terminological choice must not create barriers between overlapping research fieldsthis dynamic interaction of two languages has long been regarded as one of the most defining features of bilingualism (Kroll et al.,

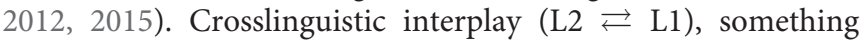
that monolinguals obviously lack, is arguably the greatest influence behind the distinctive organization and functioning of the bilingual mind and brain (Hernandez et al., 2005, 2019a; Hernandez, 2013; Li et al., 2014; Bialystok, 2017; Hayakawa and Marian, 2019). In fact, there is currently a substantial amount of empirical evidence demonstrating the specific ways in which L1 and L2 of the bilinguals are affected by one another (Kroll et al., 2012; Coderre, 2015). While the effect of a dominant L1 on a later acquired, relatively less proficient L2 might be expected and considered natural, there is also substantial evidence for an effect of the L2 on the L1. Various types of bilinguals, even in communicative contexts requiring exclusive use of their L1, exhibit certain behaviors due to unavoidable L2 influence that their monolingual peers do not-these include slower word production, decreased accuracy, lower semantic fluency, and increased tip-of-tongue states in their L1 (Bialystok et al., 2012; Costa and Sebastián-Gallés, 2014; Kroll et al., 2015). These are accepted as a natural outcome of housing two interacting language systems and are hardly ever labeled as instances of attrition. It is possible that the linguistic behaviors considered to amount to L1 attrition could be due to changes in the L1L2 dynamic, changes in the extent to which the two languages influence one another, brought on by experiential changes including migration to different sociolinguistic environments, and not just purely due to the effects of an L2 on the L1, which persist regardless in all bilinguals. Similarly, Hernandez et al. (2019b, p. 260) suggested that the bilingual system is non-linear and dynamic (Hernandez et al., 2019a) and that attrition indicates its reconfiguration(s) and repurposing to suit new contexts. This is something that attrition research has been acknowledging for 
a long time (Schmid and Köpke, 2007). Thus, as also proposed by Schmid and Köpke (2007), the relevance of L1 attrition for the theories of bilingual development is reinforced by the fact that L1 attrition appears not to be intrinsically distinct from bilingualism, but rather a feature of the latter.

To determine whether or not L1 attrition is qualitatively distinct from bilingualism as such, one would need to determine features that are attributable to L1 attrition alone. However, in nearly all attrition studies thus far $^{2}$, the L1 attriters are bilinguals, while the non-attriting controls are mostly monolinguals. Thus, the comparisons are not really between "attriters" and "nonattriters" but between those whose L1 surely receives some influence from the L2 and those whose L1 is free from it. Consequently, the findings of group-level linguistic and behavioral differences taken as an indication of L1 attrition can be seen as consequences of bilingualism and fall within the typical range of behaviors that bilinguals exhibit owing to their specific linguistic situation (e.g., see Bergmann et al., 2015b).

This interpretation is equally applicable to the existing ERP studies where the key ERP differences between attriters and monolingual controls might actually reflect a bilingualism artifact. For example, Bergmann et al. (2015a) acknowledged that the biphasic N400-P600 pattern in their bilingual attriters may reflect the relative linguistic difference between the L1 and L2 and is similar to findings reported by Sabourin and Stowe (2008), who examined how L1-L2 similarity alters language processing in (non-attriting) bilinguals. Similarly, Kasparian and Steinhauer (2016) noted that the larger P600 response that only their attriter group exhibited is possibly suggestive of increased conflict-monitoring and "re-checking" while processing anomalous lexico-semantic components in sentences. The fact that bilinguals, compared with monolinguals, rely on the increased extent of conflict monitoring while processing either language to control and manage crosslinguistic influence is empirically well established (Bialystok, 2017; Calabria et al., 2018). However, if the attriting samples in both studies were to be compared with a non-attriting bilingual group that has managed to maintain L1 use (with or without migration), it would tell us whether or not the specific P600 response (signaling increased conflict monitoring) or the biphasic responses (modulated by linguistic distance) are unique to the attriters. In this case, it could qualify as a specific L1-attriton marker; otherwise, if it is shared with bilingual controls, this would signify a bilingualism effect arising due to the presence of two interacting linguistic systems but not a distinct marker of attrition. To the best of our knowledge, no such studies have been done to date.

Thus, we supported the view that L1 attrition, characterized by a relative increase in frequency, quantity, quality, diversity of L2 use, and exposure and a possible concomitant decrease in all these aspects for the L1, be included within the spectrum of bilingual experiences. We further encouraged researchers to view attriters as a group within the bilingual spectrum and

${ }^{2}$ With the exception. of a small set of attriting monolinguals who nonetheless, in the interpretation of the same experimenters reporting this evidence, are most probably experiencing indirect attrition via interaction with attriting bilinguals (Laufer and Baladzhaeva, 2015; Baladzhaeva and Laufer, 2018). sought a better understanding of how distinct they may be, if at all. Further neurocognitive and behavioral comparisons between attriting and non-attriting bilinguals (e.g., Major, 2010; Schmid, 2014; Miller and Rothman, 2020) are needed to continue unveiling what L1 attrition really is and determine whether there are indeed linguistic behaviors and associated neurocognitive processes that are distinct and separable enough from the range of crosslinguistic bilingual effects to be characterized as L1 attrition. Findings from extant L1 attrition research also seem to reinforce the notion of "heterogeneous outcomes of heterogeneous bilingual experiences." For example, increasing length of immersion, L2 exposure, and L2 proficiency has been shown to modulate L1 ERP responses among bilingual "L1 attriters" themselves (e.g., Kasparian and Steinhauer, 2017a; Miller and Rothman, 2020). This is in line with recent findings demonstrating that variations in the aforementioned bilingual experiential factors have a discernible impact on the linguistic neurobiology, neurocognition, and behavior of the bilinguals (e.g., Gullifer et al., 2018; DeLuca et al., 2019; Gallo et al., 2021; Sulpizio et al., 2020).

Finally, we addressed the circularity problem mentioned earlier: to study L1 attrition, we already needed to have an idea of what it is and where to find it. In order to break free from the risk of circularity, i.e., defining the population of interest in terms of the concept of interest, one needs to determine and adopt attrition-free criteria for identifying the population of interest. Based on the well-documented evidence of L1 attrition effects, we stated with reasonable confidence that bilinguals immersed in an L2-dominant sociocultural environment due to migration are clearly the population of interest here-they are most likely to exhibit behavioral and neurocognitive characteristics that might differ from their bilingual peers elsewhere, especially those in L1-dominant environments. Rather than immediately labeling the migrant bilinguals as L1 attriters, we could qualify and quantify their dual-language experience accompanying migration, acculturation, and immersion in an L2-dominant region as just another variant of the bilingual experience. Comparing this L1-attrition or disuse type of bilingual experience to other experiences on the bilingual spectrum, such as the L1-maintenance experience of non-migrant bilinguals in L1dominant regions or of those who have managed to maintain active dual-language use despite migration, might generate enough empirical evidence that would allow us to deduce whether or not L1 attrition is wholly distinct and orthogonal from bilingualism.

\section{CONCLUSION}

Attrition experience is highly typical for bilinguals who have migrated to non-L1 environments, which motivates understanding of the L1 attrition phenomenon as a distinct type of bilingual experience. It is therefore important to provide comparisons involving migrant bilingual populations with suitable bilingual controls (besides monolingual ones) on linguistic behaviors as well as on the underlying neurocognitive processes. Studying L1 attrition from the vantage point of 
bilingualism would not only contribute toward enriching and informing our current understanding of bilingualism itself, but it will also offer a richer perspective on how sociocultural factors shape linguistic behaviors and processes.

\section{DATA AVAILABILITY STATEMENT}

The original contributions presented in the study are included in the article/supplementary material, further inquiries can be directed to the corresponding author/s.

\section{REFERENCES}

American Community Survey (2015). Available online at: https://factfinder.census. gov/faces/tableservices/jsf/pages/productview.xhtml?src=bkmk (accessed April 25, 2020).

Baladzhaeva, L., and Laufer, B. (2018). Is first language attrition possible without second language knowledge? IRAL Int. Rev. Appl. Linguist. Lang. Teach. 56, 103-136. doi: 10.1515/iral-2016-0066

Ben Rafael, M. (2001). Contact de Langues: Le Français Parlé des Francophones Israéliens. Ph.D. dissertation. Tel Aviv: University of Tel Aviv.

Bergmann, C., Meulman, N., Stowe, L. A., Sprenger, S. A., and Schmid, M. S. (2015a). Prolonged L2 immersion engenders little change in morphosyntactic processing of bilingual natives. Neuroreport 26, 1065-1070. doi: 10.1097/WNR. 0000000000000469

Bergmann, C., Nota, A., Sprenger, S. A., and Schmid, M. S. (2016). L2 immersion causes non-native-like L1 pronunciation in German attriters. J. Phon. 58, 71-86. doi: 10.1016/j.wocn.2016.07.001

Bergmann, C., Sprenger, S. A., and Schmid, M. S. (2015b). The impact of language co-activation on L1 and L2 speech fluency. Acta Psychol. 161, 25-35.

Bialystok, E. (2017). The bilingual adaptation: how minds accommodate experience. Psychol. Bull. 143, 233-262. doi: 10.1037/bul0000099

Bialystok, E., Craik, F. I. M., and Luk, G. (2012). Bilingualism: consequences for mind and brain. Trends Cogn. Sci. 16, 240-250. doi: 10.1016/j.tics.2012. 03.001

Calabria, M., Costa, A., Green, D. W., and Abutalebi, J. (2018). Neural basis of bilingual language control. Ann. N. Y. Acad. Sci. 1426, 221-235. doi: 10.1111/ nyas. 13879

Canada Census Program (2011). Available online at: http://www12.statcan. gc.ca/census-recensement/2011/as-sa/98-314-x/98-314-x2011001-eng.cfm (accessed April 25, 2020).

Chamorro, G., Sorace, A., and Sturt, P. (2016a). What is the source of L1 attrition? The effect of recent L1 re-exposure on Spanish speakers under L1 attrition. Bilingualism 19, 520--532.

Chamorro, G., Sturt, P., and Sorace, A. (2016b). Selectivity in L1 attrition: differential object marking in Spanish near-native speakers of English. J. Psycholinguist. Res. 45, 697-715. doi: 10.1007/s10936-015-9372-4

Coderre, E. L. (2015). "The neuroscience of bilingualism: cross-linguistic influences and cognitive effects," in Neuroscience in Intercultural Contexts, eds J. E. Warnick and D. Landis (New York, NY: Springer), 73-116. doi: 10.1007/978-14939-2260-4_4

Costa, A., and Sebastián-Gallés, N. (2014). How does the bilingual experience sculpt the brain? Nat. Rev. Neurosci. 15, 336-345. doi: 10.1038/nrn3709

de Bot, K., Gommans, P., and Rossing, C. (1991). "L1 loss in an L2 environment: Dutch immigrants in France," in First Language Attrition, eds H. W. Seliger and R. M. Vago (Cambridge: Cambridge University Press), 87-98. doi: 10.1017/ cbo9780511620720.006

de Leeuw, E., Mennen, I., and Scobbie, J. M. (2012). Singing a different tune in your native language: first language attrition of prosody. Int. J. Biling. 16, 101-116. doi: 10.1177/1367006911405576

de Leeuw, E., Schmid, M. S., and Mennen, I. (2010). The effects of contact on native language pronunciation in an L2 migrant setting. Bilingualism 13, 33-40. doi: $10.1017 /$ s1366728909990289

\section{AUTHOR CONTRIBUTIONS}

All authors listed have made a substantial, direct and intellectual contribution to the work, and approved it for publication.

\section{FUNDING}

The present study has been supported by Russian Science Foundation Grant (Project No. 19-18-00550) to the HSE University.

de Leeuw, E., Tusha, A., and Schmid, M. S. (2018). Individual phonological attrition in Albanian-English late bilinguals. Bilingualism 21, 278-295. doi: 10.1017/ S1366728917000025

DeLuca, V., Rothman, J., Bialystok, E., and Pliatsikas, C. (2019). Redefining bilingualism as a spectrum of experiences that differentially affects brain structure and function. Proc. Natl. Acad. Sci. U.S.A. 116, 7565-7574. doi: 10. 1073/pnas. 1811513116

Dijkstra, T., and Van Heuven, W. J. (2002). The architecture of the bilingual word recognition system: from identification to decision. Bilingualism 5, 175-197. doi: $10.1017 / \mathrm{s} 1366728902003012$

Dussias, P. E. (2004). Parsing a first language like a second: the erosion of L1 parsing strategies in Spanish-English bilinguals. Int. J. Biling. 8, 355-371.

Eurobarometer Report "Europeans and their languages" (2012). Available online at: https://epale.ec.europa.eu/en/resource-centre/content/eurobarometereuropeans-and-their-languages-2012 (accessed April 25, 2020).

Gallo, F., Novitskiy, N., Myachykov, A., and Shtyrov, Y. (2021). Individual differences in bilingual experience modulate executive control network and performance: behavioral and structural neuroimaging evidence. Bilingualism 24, 293-304. doi: 10.1017/S1366728920000486

Gargiulo, C., and van de Weijer, J. (2018). Recovery effects in L1 attrition: a study on anaphora resolution in Italian. Abstract from UIC Bilingualism Forum 2018. Chicago, IL: University of Illinois at Chicago.

Grosjean, F. (ed.) (2010). Bilingual. Cambridge, MA: Harvard University Press.

Gullifer, J. W., Chai, X. J., Whitford, V., Pivneva, I., Baum, S., Klein, D., et al. (2018). Bilingual experience and resting-state brain connectivity: impacts of L2 age of acquisition and social diversity of language use on control networks. Neuropsychologia 117, 123-134. doi: 10.1016/j.neuropsychologia.2018.04.037

Hayakawa, S., and Marian, V. (2019). Consequences of multilingualism for neural architecture. Behav. Brain Funct. 1:6. doi: 10.1186/s12993-019-0157-z

Hernandez, A., Li, P., and MacWhinney, B. (2005). The emergence of competing modules in bilingualism. Trends Cogn. Sci. 9, 220-225. doi: 10.1016/j.tics.2005. 03.003

Hernandez, A. E. (2013). The Bilingual Brain. Oxford: Oxford University Press.

Hernandez, A. E., Claussenius-Kalman, H. L., Ronderos, J., Castilla-Earls, A. P., Sun, L., Weiss, S. D., et al. (2019a). Neuroemergentism: a framework for studying cognition and the brain. J. Neurolinguist. 49, 214-223. doi: 10.1016/ j.jneuroling.2017.12.010

Hernandez, A. E., Claussenius-Kalman, H. L., Ronderos, J., Castilla-Earls, A. P., Sun, L., Weiss, S. D., et al. (2019b). Neuroemergentism: response to commentaries. J. Neurolinguist. 49, 258-262. doi: 10.1016/j.jneuroling.2018.06. 001

Hutz, M. (2004). "Is there a natural process of decay? A longitudinal study of language attrition," in First Language Attrition: Interdisciplinary Perspectives on Methodological Issues, eds M. S. Schmid, B. Köpke, M. Keijzer, and L. Weilemar (Amsterdam: John Benjamins Publishing), 189-206. doi: 10.1075/sibil.28.11hut

Isurin, L. (2007). Teachers' Language: L1 Attrition in Russian-English Bilinguals. Mod. Lang. J. 91, 357-371. doi: 10.1111/j.1540-4781.2007.00585.x

Karayayla, T., and Schmid, M. S. (2019). First language attrition as a function of age at onset of bilingualism: first language attainment of Turkish-English Bilinguals in the United Kingdom. Lang. Learn. 69, 106-142. doi: 10.1111/lang.12316

Kasparian, K., and Steinhauer, K. (2016). Confusing similar words: ERP correlates of lexical-semantic processing in first language attrition and late 
second language acquisition. Neuropsychologia 93, 200-217. doi: 10.1016/j. neuropsychologia.2016.10.007

Kasparian, K., and Steinhauer, K. (2017a). On missed opportunities and convenient “truths.". Linguist. Approaches Biling. 7, 709-714. doi: 10.1075/lab.00010.kas

Kasparian, K., and Steinhauer, K. (2017b). When the second language takes the lead: neurocognitive processing changes in the first language of adult Attriters. Front. Psychol. 8:389. doi: 10.3389/fpsyg.2017.00389

Kasparian, K., Vespignani, F., and Steinhauer, K. (2017). First Language Attrition Induces Changes in Online Morphosyntactic Processing and Re-Analysis: an ERP Study of Number Agreement in Complex Italian Sentences. Cogn. Sci. 41, 1760-1803. doi: $10.1111 /$ cogs. 12450

Köpke, B. (2004). "Attrition is not a unitary phenomenon: on different possible outcomes of language contact situations," in Bilingual Socialization and Bilingual Language Acquisition: Proceedings from the Second International Symposium on Bilingualism, eds A. M. L. Suarez, F. Ramallo, and X.-P. Rodiguez-Yanez (Vigo: Servizo de Publicacions da Universitdade de Vigo), 1331-1347.

Köpke, B., and Genevska-Hanke, D. (2018). First language attrition and dominance: Same or different? Front. Psychol. 9:1963. doi: 10.3389/fpsyg.2018. 01963

Köpke, B., and Schmid, M. S. (2004). "Language attrition: the next phase”, in First Language Attrition: Interdisciplinary Perspectives on Methodological Issues, eds M. Schmid, B. Köpke, M. Keijzer and L. Weilemar (Amsterdam: John Benjamins), 1-43.

Kroll, J. F., Dussias, P. E., Bice, K., and Perrotti, L. (2015). Bilingualism, mind, and brain. Annu. Rev. Linguist. 1, 377-394. doi: 10.1146/annurev-linguist-030514124937

Kroll, J. F., Dussias, P. E., Bogulski, C. A., and Kroff, J. R. V. (2012). Juggling two languages in one mind: what bilinguals tell us about language processing and its consequences for cognition. Psychol. Learn. Motiv. 56, 229-262.

Laufer, B., and Baladzhaeva, L. (2015). First language attrition without second language acquisition. ITL Int. J. Appl. Linguist. 166, 229-253. doi: 10.1075/itl. 166.2.02lau

Li, P., Legault, J., and Litcofsky, K. A. (2014). Neuroplasticity as a function of second language learning: anatomical changes in the human brain. Cortex 58 , 301-324. doi: 10.1016/j.cortex.2014.05.001

Major, R. C. (2010). First language attrition in foreign accent perception. Int. J. Biling. 14, 163-183. doi: 10.1177/1367006910363063

Miller, D., and Rothman, J. (2020). You win some, you lose some: comprehension and event-related potential evidence for L1 attrition. Bilingualism 23, 1-15. doi: 10.1017/S1366728919000737

Opitz, C. (2013). A dynamic perspective on late bilinguals' linguistic development in an L2 environment. Int. J. Biling. 17, 701-715. doi: $10.1177 / 1367006912454621$

Ribbert, A., and Kuiken, F. (2010). L2-induced changes in the L1 of Germans living in the Netherlands. Bilingualism 13, 41-48. doi: 10.1017/s1366728909990320

Sabourin, L., and Stowe, L. A. (2008). Second language processing: When are first and second languages processed similarly? Second Lang. Res. 24, 397-430. doi: 10.1177/0267658308090186

Schmid, M. E., Köpke, B. E., Cherciov, M. C., Karayayla, T. C., Keijzer, M. C., De Leeuw, E. C., et al. (2019). The Oxford Handbook of Language Attrition. Oxford: Oxford University Press.
Schmid, M. S. (2007). “The role of L1 use for L1 attrition," in Language Attrition. Theoretical Perspectives, eds B. Köpke, M. S. Schmid, M. Keijzer, and S. Dostert (Amsterdam: John Benjamins Publishing), 135-153. doi: 10.1075/sibil.33. $10 \mathrm{sch}$

Schmid, M. S. (2014). The debate on maturational constraints in bilingual development: a perspective from first-language attrition. Lang. Acquis. 21, 386-410. doi: 10.1080/10489223.2014.892947

Schmid, M. S., and Dusseldorp, E. (2010). Quantitative analyses in a multivariate study of language attrition: the impact of extralinguistic factors. Second Lang. Res. 26, 125-160. doi: 10.1177/0267658309337641

Schmid, M. S., and Jarvis, S. (2014). Lexical access and lexical diversity in first language attrition. Bilingualism 17, 729-748. doi: 10.1017/S136672891300 0771

Schmid, M. S., and Köpke, B. (2007). "Bilingualism and attrition," in Language Attrition. Theoretical Perspectives, eds B. Köpke, M. S. Schmid, M. Keijzer, and S. Dostert (Amsterdam: John Benjamins Publishing), 1-7. doi: 10.1075/sibil.33. $02 \mathrm{sch}$

Schmid, M. S., and Köpke, B. (2017a). The relevance of first language attrition to theories of bilingual development. Linguist. Approaches Biling. 7, 637-667. doi: 10.1075/lab.17058.sch

Schmid, M. S., and Köpke, B. (2017b). When is a bilingual an attriter? Response to the commentaries. Linguist. Approaches Biling. 7, 763-770. doi: 10.1075/lab. 17059.sch

Schmid, M. S., and Yilmaz, G. (2018). Predictors of language dominance: an integrated analysis of first language attrition and second language acquisition in late bilinguals. Front. Psychol. 9:1306. doi: 10.3389/fpsyg.2018. 01306

Smith, M. S. (2019). Language Attrition as a Special Case of Processing Change: A Wider Cognitive Perspective, 1st Edn, eds M. Schmid and B. Köpke (Oxford: Oxford University Press). doi: 10.1093/oxfordhb/9780198793595.013.7

Sulpizio, S., Del Maschio, N., Del Mauro, G., Fedeli, D., and Abutalebi, J. (2020). Bilingualism as a gradient measure modulates functional connectivity of language and control networks. Neuroimage 205:116306. doi: 10.1016/j. neuroimage.2019.116306

United Nations (2018). International Migration Report 2017-Highlights. New York, NY: UN.

Ventureyra, V. A., Pallier, C., and Yoo, H. Y. (2004). The loss of first language phonetic perception in adopted Koreans. J. Neurolinguist. 17, 79-91. doi: 10. 1016/s0911-6044(03)00053-8

Yilmaz, G., and Schmid, M. S. (2012). L1 accessibility among Turkish-Dutch bilinguals. Ment. Lex. 7, 249-274. doi: 10.1075/ml.7.3.01yil

Conflict of Interest: The authors declare that the research was conducted in the absence of any commercial or financial relationships that could be construed as a potential conflict of interest.

Copyright (c) 2021 Gallo, Ramanujan, Shtyrov and Myachykov. This is an open-access article distributed under the terms of the Creative Commons Attribution License (CC BY). The use, distribution or reproduction in other forums is permitted, provided the original author(s) and the copyright owner(s) are credited and that the original publication in this journal is cited, in accordance with accepted academic practice. No use, distribution or reproduction is permitted which does not comply with these terms. 